CLINICAL STUDY

\title{
Serum GH and IGF-I are significant determinants of bone turnover but not bone mineral density in active acromegaly: a prospective study of more than 70 consecutive patients
}

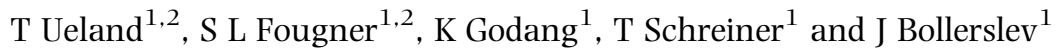 \\ ${ }^{1}$ Section of Endocrinology and ${ }^{2}$ Research Institute for Internal Medicine, Rikshospitalet University Hospital, University of Oslo, N-O027 Oslo, Norway \\ (Correspondence should be addressed to T Ueland; Email: thor.ueland@medisin.uio.no)
}

\begin{abstract}
Objective: Acromegaly is characterized by a persistent hypersecretion of GH and provides information on long-term effects of GH on bone metabolism. The aim of this study was to examine the effect of gonadal status and disease activity on bone metabolism in active acromegaly.

Methods: Seventy-three consecutive patients with active acromegaly: 40 women and 33 men ( $50 \pm 13$ (mean \pm s.D.) and $49 \pm 10$ years respectively) were evaluated and compared with age-, sex-, and body mass index (BMI)-matched controls by X-ray absorptiometry and biochemical analysis (markers of disease activity and bone turnover).

Results: We found that bone turnover, as evaluated by biochemical bone markers, is coupled and markedly increased in relation to disease activity in active acromegaly. Acromegalic women, but not men, were characterized by an increased bone area and slightly decreased bone mineral content resulting in significantly decreased bone mineral density (BMD) in the ultradistal radius, proximal radius, and total body. No differences in bone turnover or BMD were found between eu-and hypogonadal subjects. Multivariate analysis identified age, BMI, and gender as independent predictors of total BMD in acromegaly.

Conclusion: Our study demonstrates a decreased total body BMD in women, not men, with active acromegaly, regardless of gonadal status or disease activity. Bone turnover is markedly increased in relation to disease activity, possibly counteracting the anabolic effects of excess GH/IGF-I in these subjects. We suggest more focus on biomechanical analyses when investigating endocrine disorders affecting bone size and distribution between compartments.
\end{abstract}

European Journal of Endocrinology 155 709-715

\section{Introduction}

Acromegaly serves as a model of hypersomatotropism, where the effects of chronic systemic growth hormone (GH) and insulin-like growth factor-I (IGF-I) excess on skeletal metabolism in adults can be studied. Bone turnover is increased, suggesting activation of both osteoblasts and osteoclasts in active acromegaly (1-7). Moreover, biochemical markers of bone formation and bone resorption correlate with circulating GH and IGF-I levels suggesting that GH and liver-derived IGF-I may have direct effects on both cell types in modulating turnover $(1,2,8,9)$. However, in recent years the importance of liver-derived IGF-I has been questioned, in particular in relation to effects on bone metabolism $(10,11)$.

While many studies describe increased cortical bone mass in acromegaly, data regarding trabecular bone are conflicting. In fact, acromegaly was traditionally associated with osteoporosis (12-14). Later studies have revealed a differential effect of $\mathrm{GH}$ excess on the axial (70\% trabecular bone) and appendicular skeleton
(90\% cortical bone) with unchanged or reduced vertebral bone density and increased forearm bone density $(1,3$, 13-17), while some studies show no differences in acromegalic patients compared with normal controls $(4,18,19)$. However, measurement of bone mineral density (BMD) in the axial skeleton, as an indicator of trabecular bone mass, may be overestimated in endocrine disorders affecting bone size and the distribution between trabecular and cortical envelopes. Accordingly, we recently found reduced trabecular biomechanical competence in subjects with active acromegaly (20). Still, only few studies have reported increased fracture frequency in these patients, possibly due to protective effects of increased bone size and cortical mass. However, a recent study demonstrated a high prevalence of vertebral fractures in postmenopausal women with acromegaly in relation to disease activity (21). Thus, gonadal status has been proposed to be an important determinant of excess $\mathrm{GH}(7,13,15,17)$, and it is possible that trabecular bone, with its more intimate contact with the circulation, is influenced by sex steroids to a greater extent. 
To elucidate further the effect of gonadal status and disease activity on bone metabolism in active acromegaly, we have evaluated the gonadal function and disease activity of 73 consecutive patients with active acromegaly using stringent clinical and biochemical parameters and related these to bone mass by osteodensitometry and biochemical markers of bone turnover.

\section{Subjects and methods}

\section{Subjects}

Seventy-three patients with active acromegaly were included in this cross-sectional study. All patients were examined at the Section of Endocrinology, Rikshospitalet University Hospital, in the period 1996-2005. At the time of evaluation, 69 patients were diagnosed recently. The remaining four patients had previously undergone a transsphenoidal adenomectomy with postoperatively persistent activity of the disease for several years. None had received radiation therapy or somatostatin analog treatment. Acromegaly was diagnosed by elevated serum IGF-1 compared with the normal reference range of their age and failure of suppression of $\mathrm{GH}$ below $5 \mathrm{mU} / \mathrm{l}$ after a $75 \mathrm{~g}$ oral glucose load. In all patients, a pituitary adenoma was visualized on magnetic resonance imaging scan. A group of 40 healthy subjects (colleagues, friends, and family) matched by age, sex, and body mass index (BMI) was used as controls. Gonadal status was categorized in patients using the following criteria: Men were considered eugonadal if serum total testosterone > $12 \mathrm{nmol} / \mathrm{l}$, or if s-testosterone was $7.5-12 \mathrm{nmol} / \mathrm{l}$, but the calculated free testosterone $>0.225 \mathrm{nmol} / \mathrm{l}$ and calculated bioavailable testosterone $>5.3 \mathrm{nmol} / \mathrm{l}(22-$ 24). Women were considered hypogonadal if they had oligo- or amenorrhea for 6 months. An estimate of duration of hypogonadism was obtained in 16 out of the 19 hypogonadal women. Women treated with estrogens and men treated with testosterone were considered eugonadal. Details on gonadal status in patients and controls are given in Table 1 . The duration of acromegaly $(n=55)$ was estimated to be (mean and range) 8 years (1-20). The study was approved by the local ethical committee and conducted according to the Declaration of Helsinki II. Informed consent was obtained from patients and controls.

\section{Osteodensitometric measurements}

Bone mineral content (BMC; g), bone area $\left(\mathrm{cm}^{2}\right)$, and BMD $\left(\mathrm{g} / \mathrm{cm}^{2}\right)$ of the total body were measured using dual-energy X-ray absorptiometry (DXA), (Lunar DPXL, software version 4.6c, Lunar Corporation, Madison, WI, USA), (25). In addition to total body with the subregions arms, legs, and trunk, osteodensitometric measurements were performed in the lumbar spine,
Table 1 Baseline characteristics of the study population. Data are given as mean \pm s.D.

\begin{tabular}{lccc}
\hline & Acromegaly & Controls & $P$ value \\
\hline Demographics & & & \\
$\quad n$ & 73 & 40 & $\mathrm{ND}$ \\
Age (years) & $51 \pm 10$ & $49 \pm 11$ & 0.835 \\
Women/men $(n)$ & $40 / 33$ & $25 / 15$ & 0.517 \\
BMl (kg/m $\left.{ }^{2}\right)$ & $28.4 \pm 4.4$ & $27.9 \pm 4.0$ & 0.428 \\
Gonadal status & $9(27 \%)$ & $0(0 \%)$ & 0.033 \\
$\quad$ Men, hypogonadal $(n, \%)$ & $19(48 \%)$ & $5(21 \%)^{\mathrm{a}}$ & 0.025 \\
$\quad$ Women, hypogonadal $(n, \%)$ & & & \\
Biochemistry & & & \\
GH (mU/l) & $45.4 \pm 57.1$ & $3.6 \pm 6.6$ & $P<0.001$ \\
IGF-I (nmol/l) & $84.1 \pm 25.3$ & $20.8 \pm 5.7$ & $P<0.001$ \\
IGFBP-3 (nmol/l) & $145 \pm 27$ & $62 \pm 21$ & $P<0.001$ \\
\end{tabular}

BMI, body mass index; GH, growth hormone; IGF, insulin-like growth factor; IGFBP, IGF-binding protein.

${ }^{a}$ Gonadal status not known is one female control.

femoral neck, and forearm. BMD Z-scores are given with reference to normative data provided from the manufacturer. In 11 out of the 69 de novo patients, the DXA scan was performed postoperatively within 3 months.

\section{Biochemical measurements}

Blood samples were drawn after an overnight fast, serum isolated, and stored at $-80{ }^{\circ} \mathrm{C}$ until analyzed. Serum IGF-1 was measured by RIA in all subjects (for diagnosis purposes) and $\mathrm{GH}$ was measured after an overnight fast by immunoassay (detection limit $0.3 \mathrm{mU} / \mathrm{l})$. Over the years different methods were used; however, at every change of method, cross-calibration was performed and, if necessary, factorial adjustments performed. In addition, in all patients, additional three to seven blood samples for measurement of $\mathrm{GH}$ were drawn during daytime $(0800-1500 \mathrm{~h})$ for calculation of mean GH level. The following analyses were performed, each in one run, if possible in order to minimize run-to-run variability: serum IGFBP3 was measured by RIA (Nichols Institute, Nijmegen, The Netherlands), the bone formation marker osteocalcin was measured by IRMA, (Incstar Corporation, Stillwater, MI, USA), and degradation products of the C-terminal telopeptides of type I collagen (CTX-1) were measured in serum by ELISA (Serum Crosslaps, Nordic Bioscience Diagnostics A/S, Herlev, Denmark). Serum IGF-1 was also measured in one run (RIA, Nichols Institute, Nijmegen, The Netherlands), and compared with previous values, giving a correlation coefficient of $0.86(P<0.001)$. In patients without serum available, the previous measurement with the same assay used for diagnosis purposes was used. Intra- and interassay coefficients of variation (CVs) were $<10 \%$ for all assays.

\section{Statistics}

Differences between groups were analyzed with the Mann-Whitney rank sum test. Relationships between 
variables were tested by Spearman correlation analysis. Differences in proportions were analyzed using Chisquared test. To determine the independent predictors of bone mass, we used simple linear (bivariate) regression analysis. A subsequent multiple linear regression analysis was performed with stepwise addition of the variables that had $P$ values $<0.1$ in our $a$ priori analysis and upon bivariate regression. $P$ values are two-sided and considered significant when $<0.05$.

\section{Results}

\section{Disease activity}

Characteristics of the study population are given in Table 1 showing markedly higher GH, IGF-I, and IGFBP3 in acromegalic patients compared with controls. Due to the diurnal variation in $\mathrm{GH}$, multiple sampling has been suggested as the best marker of disease severity and GH activity in acromegaly. Therefore, we correlated fasting (08:00 value) $\mathrm{GH}$ and different expressions of $\mathrm{GH}$ day curve including highest $(r=0.96)$, lowest $(r=0.95)$, and mean GH $(r=0.97)$. Since there is a strong correlation between the mean value of the day curve and fasting $\mathrm{GH}$, we used fasting $\mathrm{GH}$ throughout the calculations, because other biochemical parameters were obtained at the same time. Regardless of GH value used, similar results were obtained using fasting or average $\mathrm{GH}$ in multivariate analysis. No gender differences were observed in acromegalic patients for IGF-1 or GH (data not shown). Gonadal status had no influence on GH or IGF-1 when investigating the total patient population, or when subdivided according to gender (data not shown). Eleven subjects (five women) had prolactin above upper limit of normal, and six out of them (two women) were hypogonadal. Two patients had hypothyroidism and none had manifest hypocortisolism, assessed by fasting morning blood sampling. Excluding the two patients with hypothyroidism had no impacts on the results (below).

\section{Bone turnover}

Bone turnover as estimated by biochemical bone markers was markedly increased in acromegaly patients (Fig. 1) with a trend toward a higher turnover in men compared with women for osteocalcin $(14.9 \pm 1.7 \mathrm{vs} 10.9 \pm 1.3 \mathrm{ng} /$ $\mathrm{ml}, P=0.094)$ and CTX-1 (1.23 \pm 0.15 vs $0.86 \pm$ $0.10 \mathrm{ng} / \mathrm{ml}, P=0.058)$. Again, gonadal status had no influence on turnover parameters. Furthermore, osteocalcin and CTX-1 were positively correlated in patients (and controls; Fig. 1) suggesting that bone turnover is synchronized (coupling). This correlation was present in both genders (data not shown). The multivariate analysis identified age (explaining 22.7\%), GH (14.8\%), and IGF-I $(6.7 \%)$ as independent predictors of CTX-I, while age
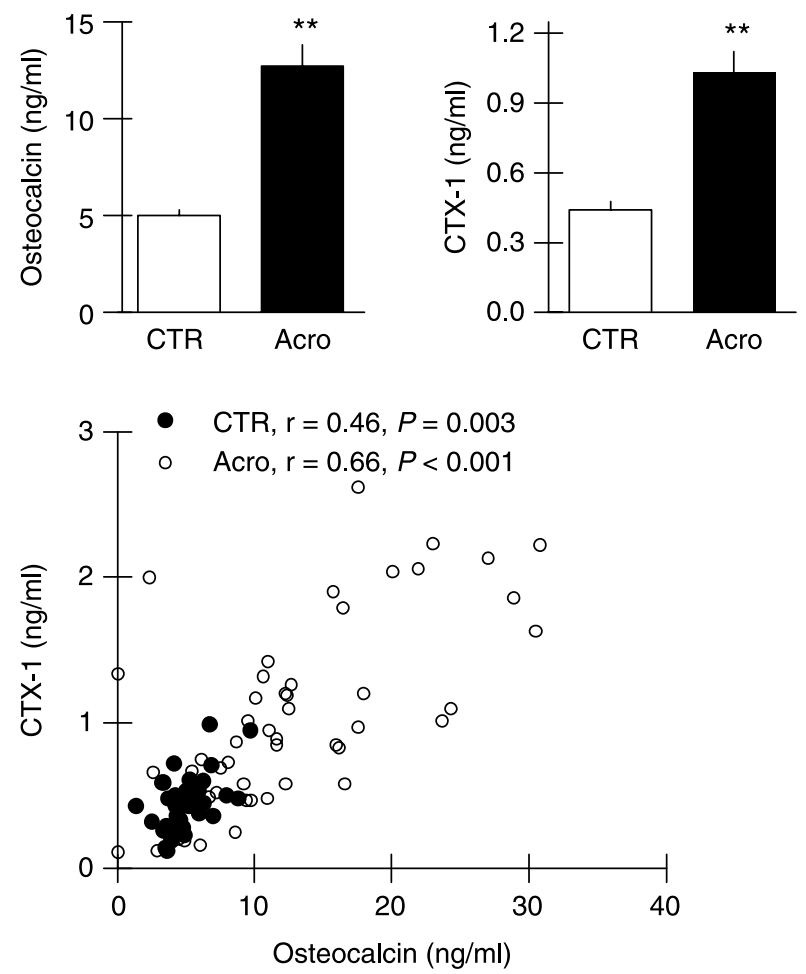

Figure 1 Serum levels of osteocalcin and type 1 collagen (CTX-1) in active acromegaly (Acro) compared with matched controls (CTR). The correlation figure shows the relationship between osteocalcin and CTX-1 in both controls and patients indicating a synchronized bone turnover. ${ }^{* \star} P<0.001$ vs controls.

(31.0\%) and IGF-I (7.6\%) were independent determinants of osteocalcin (Table 2).

\section{Bone mass}

No differences were found when comparing BMC in acromegalic patients and controls, while bone area in the femoral neck and ultradistal and proximal radius

Table 2 Determinants of bone turnover in acromegalic patients.

\begin{tabular}{|c|c|c|c|c|}
\hline \multirow[b]{2}{*}{ Variable } & \multicolumn{2}{|c|}{ Univariate analyses } & \multicolumn{2}{|c|}{ Multivariate analyses } \\
\hline & $\beta$ & $P$ & $\beta$ & $P$ \\
\hline \multicolumn{5}{|l|}{ For CTX-1 } \\
\hline Age & -0.48 & $<0.001$ & -0.36 & 0.003 \\
\hline Gender & 0.29 & 0.043 & & \\
\hline $\mathrm{GH}$ & 0.42 & 0.002 & 0.32 & 0.007 \\
\hline IGF-1 & 0.47 & 0.001 & 0.28 & 0.023 \\
\hline \multicolumn{5}{|c|}{ For Osteocalcin } \\
\hline Age & -0.56 & $<0.001$ & -0.46 & $<0.001$ \\
\hline Gender & 0.26 & 0.068 & & \\
\hline $\mathrm{GH}$ & 0.26 & 0.086 & & \\
\hline IGF-1 & 0.44 & 0.001 & 0.29 & 0.019 \\
\hline
\end{tabular}

Univariate analysis was performed on age, gender, gonadal status, body mass index, growth hormone $(\mathrm{GH})$, and insulin-like growth factor (IGF)-I and included in Multivariate analysis if $P<0.1$ (shown in table). Independent predictors were identified using multivariate models following stepwise forward selection. CTX-1, type 1 collagen. 
Table 3 Bone mass and density in acromegaly and matched controls. Data are given as mean \pm s.D.

\begin{tabular}{|c|c|c|c|c|c|c|}
\hline & \multicolumn{2}{|c|}{ Total group } & \multicolumn{2}{|c|}{ Women } & \multicolumn{2}{|c|}{ Men } \\
\hline & Acromegaly & Controls & Acromegaly & Controls & Acromegaly & Controls \\
\hline \multicolumn{7}{|l|}{ Lumbar spine } \\
\hline BMC (g) & $63.9 \pm 17.3$ & $59.1 \pm 13.1$ & $55.8 \pm 13.0$ & $54.1 \pm 13.0$ & $73.7 \pm 16.9$ & $67.4 \pm 8.6$ \\
\hline Area $\left(\mathrm{cm}^{2}\right)$ & $51.2 \pm 7.1$ & $51.5 \pm 22.0$ & $46.5 \pm 5.0$ & $49.6 \pm 27.7$ & $56.8 \pm 4.7$ & $54.6 \pm 4.1$ \\
\hline $\mathrm{BMD}\left(\mathrm{g} / \mathrm{cm}^{2}\right)$ & $1.24 \pm 0.23$ & $1.20 \pm 0.22$ & $1.20 \pm 0.22$ & $1.18 \pm 0.26$ & $1.29 \pm 0.23$ & $1.24 \pm 0.13$ \\
\hline \multicolumn{7}{|l|}{ Femoral neck } \\
\hline $\mathrm{BMC}(\mathrm{g})$ & $5.48 \pm 1.32$ & $5.23 \pm 0.99$ & $4.67 \pm 0.76$ & $4.76 \pm 0.78$ & $6.48 \pm 1.16$ & $6.02 \pm 0.79$ \\
\hline Area $\left(\mathrm{cm}^{2}\right)$ & $5.49 \pm 0.62^{*}$ & $5.24 \pm 0.60$ & $5.08 \pm 0.42$ & $4.89 \pm 0.36$ & $5.99 \pm 0.42$ & $5.99 \pm 0.425$ \\
\hline $\operatorname{BMD}\left(\mathrm{g} / \mathrm{cm}^{2}\right)$ & $0.99 \pm 0.17$ & $1.00 \pm 0.13$ & $0.92 \pm 0.14$ & $0.97 \pm 0.14$ & $1.08 \pm 0.17$ & $1.03 \pm 0.12$ \\
\hline \multicolumn{7}{|l|}{ Ultradistal radius } \\
\hline $\mathrm{BMC}(\mathrm{g})$ & $2.34 \pm 0.80$ & $2.20 \pm 0.52$ & $1.77 \pm 0.34$ & $1.91 \pm 0.29$ & $3.01 \pm 0.65$ & $2.69 \pm 0.46$ \\
\hline Area $\left(\mathrm{cm}^{2}\right)$ & $6.27 \pm 0.78^{\star}$ & $5.92 \pm 0.74$ & $5.72 \pm 0.54^{\star}$ & $5.48 \pm 0.42$ & $6.91 \pm 0.48$ & $6.65 \pm 0.55$ \\
\hline $\operatorname{BMD}\left(\mathrm{g} / \mathrm{cm}^{2}\right)$ & $0.37 \pm 0.10$ & $0.37 \pm 0.06$ & $0.31 \pm 0.06^{\star}$ & $0.35 \pm 0.05$ & $0.44 \pm 0.10$ & $0.41 \pm 0.06$ \\
\hline \multicolumn{7}{|l|}{ Proximal radius } \\
\hline BMC $(g)$ & $3.89 \pm 1.03$ & $3.64 \pm 0.61$ & $3.15 \pm 0.47$ & $3.27 \pm 0.41$ & $4.77 \pm 0.80^{*}$ & $4.26 \pm 0.29$ \\
\hline Area $\left(\mathrm{cm}^{2}\right)$ & $5.24 \pm 0.72^{\ddagger}$ & $4.79 \pm 0.48$ & $4.74 \pm 0.32^{\dagger}$ & $4.52 \pm 0.31$ & $5.84 \pm 0.59^{\ddagger}$ & $5.24 \pm 0.34$ \\
\hline $\operatorname{BMD}\left(\mathrm{g} / \mathrm{cm}^{2}\right)$ & $0.74 \pm 0.12$ & $0.76 \pm 0.08$ & $0.67 \pm 0.10^{*}$ & $0.72 \pm 0.07$ & $0.82 \pm 0.10$ & $0.82 \pm 0.07$ \\
\hline \multicolumn{7}{|l|}{ Total body } \\
\hline $\mathrm{BMC}(\mathrm{g})$ & $2993 \pm 667$ & $2972 \pm 522$ & $2576 \pm 445$ & $2687 \pm 369$ & $3498 \pm 528$ & $3446 \pm 375$ \\
\hline Area $\left(\mathrm{cm}^{2}\right)$ & $2570 \pm 380$ & $2444 \pm 325$ & $2301 \pm 233$ & $2248 \pm 184$ & $2896 \pm 242$ & $2772 \pm 231$ \\
\hline $\operatorname{BMD}\left(\mathrm{g} / \mathrm{cm}^{2}\right)$ & $1.15 \pm 0.12^{\dagger}$ & $1.21 \pm 0.09$ & $1.11 \pm 0.10^{\dagger}$ & $1.19 \pm 0.09$ & $1.20 \pm 0.11$ & $1.24 \pm 0.08$ \\
\hline
\end{tabular}

BMC, bone mineral content; BMD, bone mineral density. ${ }^{\star} P<0.05,{ }^{\dagger} P<0.01,{ }^{\ddagger} P<0.001$ vs controls.

was increased in the patients (Table 3). Total body BMD was reduced in patients due to unchanged $\mathrm{BMC}$ and insignificantly increased bone area (Fig. 2, Table 3). This was mainly due to the influence of the extremities on total BMD (data not shown). In particular, acromegalic women were characterized by an increased bone area and slightly decreased BMC resulting in significantly decreased BMD (Table 3) and T-/Z-scores (Table 4) in the ultradistal radius, proximal radius, and total body. No significant differences were found for acromegalic men, except a higher BMC and bone area in the proximal radius. According to WHO guidelines for diagnosis of osteopenia and osteoporosis, the numbers were 18 and $4 \%$ respectively in acromegalic patients. Using duration of acromegaly either as a continuous variable or after dichotomizing, we found a negative association between duration and total Z-score BMD $(P=0.021$, when comparing patients with a duration of more or less than 10 years). However, we have not included it in the regression model (see below) because of the imprecise nature of the estimates and we were unable to obtain an estimate in 18 points.

\section{Bone mass in relation to gonadal status}

When investigating bone mass in relation to gonadal status, we compared Z-scores between eu- and hypogonadal patients, since the hypogonadal group was older and age may account for the observed differences. We found no significant differences in bone mass at any site in relation to gonadal status, although hypogonadal patients generally showed lower scores (Fig. 3). Looking at women separately, excluding hypogonadal women (both controls and patients) did not change the results (i.e. a similar pattern was observed as described above, Table 4). No significant differences were observed when comparing Z-scores between female hypogonadal controls and patients separately, although similar differences as those described for the whole female population were observed. Thus, gonadal status did not significantly influence the results in our study; however, as for the comparison between hypogondal female patients and controls, caution is needed since the controls were not matched with regard to gonadal status originally. No correlation was found between duration of the untreated hypogonadism and total BMD $(r=-0.18), T$-score $(r=-0.14)$, or Z-score $(r=0.23)$; however, a correlation between duration hypogonadism and patient age was present $(r=0.85, P<0.001)$. No significant difference in BMD was found between the postmenopausal women and the women with hypogonadism due to the pituitary tumor (data not shown); however, these groups varied in size and were not optimal for making these comparisons.

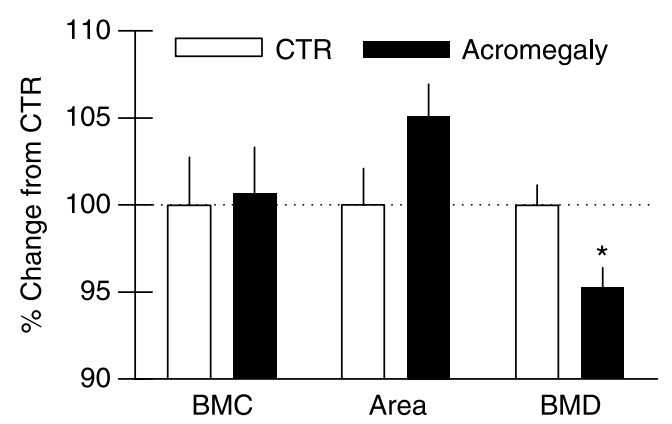

Figure 2 Differences in total BMC, BMD, and bone area between patients with active acromegaly (Acro) and matched controls (CTR) expressed as percent (controls set to $100 \%$ ). BMC, bone mineral content; BMD, bone mineral density. ${ }^{*} P<0.01$ vs controls. 
Table $4 T$ - and Z-scores in acromegaly and matched controls. Data are given as mean \pm s.D.

\begin{tabular}{|c|c|c|c|c|c|c|}
\hline & \multicolumn{2}{|c|}{ Total group } & \multicolumn{2}{|c|}{ Women } & \multicolumn{2}{|c|}{ Men } \\
\hline & Acromegaly & Controls & Acromegaly & Controls & Acromegaly & Controls \\
\hline \multicolumn{7}{|c|}{ Lumbar spine } \\
\hline$T$-score & $0.2 \pm 1.9$ & $0.1 \pm 1.4$ & $0.0 \pm 1.9$ & $0.1 \pm 1.5$ & $0.4 \pm 1.9$ & $0.0 \pm 1$ \\
\hline Z-score & $0.2 \pm 1.9$ & $0.1 \pm 1.3$ & $0.3 \pm 1.9$ & $0.3 \pm 1.3$ & $0.3 \pm 1.9$ & $-0.3 \pm 1$ \\
\hline \multicolumn{7}{|c|}{ Femoral neck } \\
\hline$T$-score & $-0.2 \pm 1.2$ & $-0.1 \pm 1.1$ & $-0.5 \pm 1.1$ & $-0.1 \pm 1.2$ & $0.1 \pm 1.3$ & $-0.3 \pm 1.0$ \\
\hline Z-score & $0.1 \pm 1.0$ & $0.2 \pm 0.9$ & $-0.1 \pm 0.9$ & $0.2 \pm 0.9$ & $0.3 \pm 1.1$ & $0.1 \pm 0.9$ \\
\hline \multicolumn{7}{|c|}{ Ultradistal radius } \\
\hline$T$-score & $-0.3 \pm 2.3$ & $0.1 \pm 1.5$ & $-1.2 \pm 1.7^{\dagger}$ & $0.1 \pm 1.5$ & $0.7 \pm 2.4$ & $0.1 \pm 1.5$ \\
\hline Z-score & $0.0 \pm 2.1$ & $0.4 \pm 1.4$ & $-0.8 \pm 1.5^{\dagger}$ & $0.3 \pm 1.3$ & $0.9 \pm 2.3$ & $0.4 \pm 1.5$ \\
\hline \multicolumn{7}{|c|}{ Proximal radius } \\
\hline$T$-score & $-0.5 \pm 1.3^{\star}$ & $0.0 \pm 0.9$ & $-0.8 \pm 1.4^{\star}$ & $0.0 \pm 0.9$ & $-0.2 \pm 1.2$ & $-0.1 \pm 0.9$ \\
\hline Z-score & $-0.2 \pm 1.0^{*}$ & $0.2 \pm 0.7$ & $-0.3 \pm 1.0^{*}$ & $0.3 \pm 0.7$ & $-0.1 \pm 1.1$ & $0.1 \pm 0.8$ \\
\hline \multicolumn{7}{|l|}{ Total body } \\
\hline$T$-score & $-0.2 \pm 1.3^{\dagger}$ & $0.6 \pm 1.1$ & $-0.1 \pm 1.3^{\dagger}$ & $0.8 \pm 1.2$ & $-0.2 \pm 1.4$ & $0.3 \pm 1.0$ \\
\hline Z-score & $-0.5 \pm 1.2^{\ddagger}$ & $0.3 \pm 1.1$ & $-0.2 \pm 1.1^{\dagger}$ & $0.7 \pm 1.0$ & $-0.9 \pm 1.3$ & $-0.3 \pm 0.9$ \\
\hline
\end{tabular}

${ }^{\star} P<0.05,{ }^{\dagger} P<0.01,{ }^{\ddagger} P<0.001$ vs controls.

\section{Multivariate analysis}

The multivariate analysis identified age (explaining $38.9 \%)$, BMI $(9.0 \%)$, and gender $(3.6 \%)$ as independent predictors of total BMD in acromegaly, while IGF-I $(30.0 \%)$ was the only independent determinant of total BMD in controls (Table 5).

\section{Discussion}

The markedly enhanced bone turnover found in patients with active acromegaly in this study is in accordance with previous studies using biochemical markers, calcium kinetics, and histomorphometry (1-7). Furthermore, biochemical markers of bone formation and bone resorption correlated well with circulating GH and IGF-I levels. Thus, GH and liverderived IGF-I may have direct effects on both cell types in modulating bone turnover $(1,8,9,26,27)$. However, our regression analyses identified $\mathrm{GH}$ and IGF-I as independent predictors of bone resorption, while only IGF-I predicted bone formation. Accordingly, in vitro experiments on human bone cells show that both $\mathrm{GH}$ and IGF-I stimulate osteoclastic bone resorption through direct and indirect actions on osteoclast formation, differentiation, and activity (28-31). However, while GH and IGF-I may regulate osteoblast proliferation, IGF-I alone has important effects on the differentiated osteoblast and many of the effects of $\mathrm{GH}$ are via endogenously produced IGFs (32). We have previously shown that acromegalic patients have elevated cortical, but not trabecular bone matrix protein levels of IGFs-I and II and IGFBP5, substantiating that the actions of $\mathrm{GH}$ are partly mediated by local production of IGFs secondary to increased circulating GH and/or IGF-I, and that these effects differ dependent on bone compartment studied $(20,33)$. As demonstrated previously, we found no effect of gender or gonadal status on bone turnover markers in the acromegalic group. Future studies investigating the impact of changes in disease activity GH/IGF-I on bone turnover during longitudinal follow-up would provide additional valuable information on these relationships.

Inconsistent data exist regarding bone mass and BMD in acromegaly, possibly due to comparison of different skeletal sites, disease activity, sex, gonadal status, and often a limited number of patients. The strength of the present study is the large sample size of wellcharacterized patients with regard to gonadal status and disease activity. Furthermore, we used multiple linear regression to estimate the impact of gonadal status and disease activity on bone mass. We found no significant differences in BMD at any site compared with
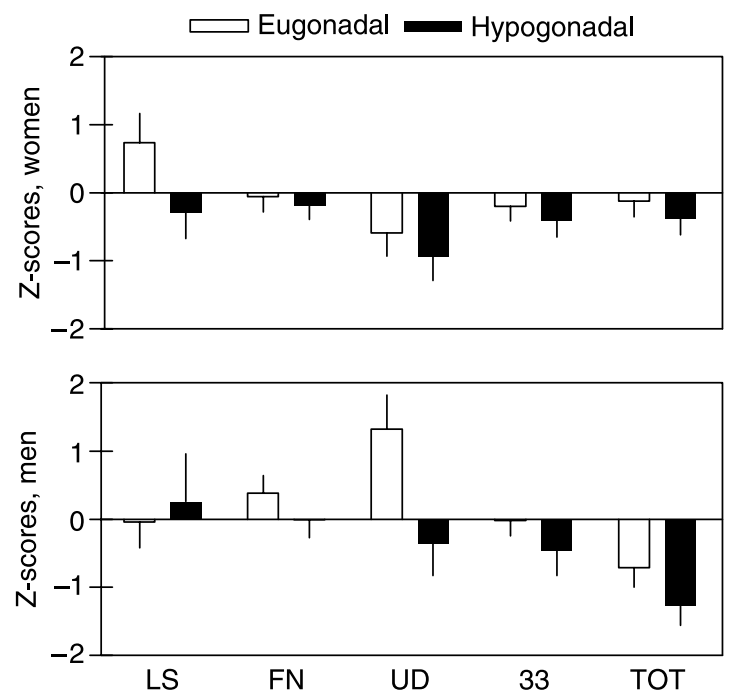

Figure 3 Effect of gonadal status on bone mineral density expressed as $Z$-scores in different compartments in patients with active acromegaly. LS, lumbar spine; FN, femoral neck; UD, ultradistal radius; 33 , proximal radius; TOT, total body. No significant differences were found. 
Table 5 Determinants of total bone mineral density (BMD) in acromegalic patients.

\begin{tabular}{|c|c|c|c|c|}
\hline \multirow[b]{2}{*}{ Variable } & \multicolumn{2}{|c|}{ Univariate analyses } & \multicolumn{2}{|c|}{$\begin{array}{c}\text { Multivariate } \\
\text { analyses }\end{array}$} \\
\hline & $\beta$ & $P$ & $\beta$ & $P$ \\
\hline \multicolumn{5}{|c|}{ For BMD in acromegaly } \\
\hline Age & -0.53 & $<0.001$ & -0.59 & $<0.001$ \\
\hline Gender & 0.39 & 0.001 & 0.23 & 0.030 \\
\hline Gonadal status & 0.26 & 0.028 & & \\
\hline BMI & 0.26 & 0.028 & 0.26 & 0.016 \\
\hline IGF-1 & 0.21 & 0.080 & & \\
\hline Osteocalcin & 0.28 & 0.053 & & \\
\hline
\end{tabular}

Univariate analysis was performed on age, gender, gonadal status, BMI, IGF-I and osteocalcin and included in multivariate analysis if $P<0.1$ (shown in table). Independent predictors were identified using multivariate models following stepwise forward selection.

matched controls, except total body BMD in acromegalic women due to low BMC and increased bone area in peripheral sites. This may be explained by increased periosteal apposition and increased bone remodeling space induced by excess $\mathrm{GH}$. A relative increase in bone turnover and cortical bone mass may counteract the anabolic effect of $\mathrm{GH}$ and further account for the lack of a direct relationship between serum GH/IGF-I and bone mass or BMD in our patients. Although no association between serum osteocalcin or CTX-1 and BMD was demonstrated, this does not exclude a relationship. Previous studies show poor correlation between biochemical markers of bone turnover and bone remodeling at the tissue level as given by histomorphometry (5).

In contrast to some previous studies $(7,13,15)$, but in agreement with others $(4,6,19)$, we found no effect of gonadal status, regardless of gender, on bone mass or BMD in acromegalic patients in this study. In general, the Z-scores were lower in hypogonadal patients and the lack of significance could be due to a type 2 error ( $n$ to small). The discrepancy that our female patients, not our male patients, had a decreased total BMD, while lower Z-scores of total BMD were observed in males compared with females, is probably due to a higher proportion of Norwegian middle-aged men than women are classified as osteoporotic and osteopenic (34).

Indeed, this paper suggests that clinical evaluation of Norwegian patients based on Z-scores from the Lunar reference data should be conducted with caution. Thus, BMD is good for comparing patients and controls, while Z-scores may be more useful for comparing the effect of gonadal status between patients. Still, to our knowledge the present study is the second largest to date evaluating bone metabolism in active acromegaly. Importantly, although the cause of hypogonadism in these patients is not age-related, the hypogonadal group tended to be older substantiating the importance of adjusting for age in the multivariate analysis, since other age-related factors may determine bone mass. In fact, the significant association between gonadal status and BMD found in univariate testing disappeared in the multivariate analysis confirming the importance of age and gender. This does not exclude gonadal status as a determinant of bone mass in acromegalic subjects but further suggests that this association is complex and that age and sex are more dominant determinants in these patients, indicating that the same mechanisms regulating bone loss in the normal population are present in acromegalic patients. However, a recent study of postmenopausal acromegalic women demonstrated that in subjects with active disease, increased fracture frequency was observed regardless of BMD, however, dependent on disease activity (21). Thus, the clinical relevance of decreased BMD in these subjects is questionable, whereas studying biomechanical properties may be of more relevance.

In conclusion, our study demonstrates a slightly decreased total body BMD in women, not men, with active acromegaly regardless of gonadal status or disease activity. Bone turnover is markedly increased in relation to disease activity, possibly counteracting the anabolic effects of excess GH/IGF-I in these subjects. We suggest more focus on biomechanical analyses when investigating endocrine disorders affecting bone size and distribution between compartments.

\section{References}

1 Ezzat S, Melmed S, Endres D, Eyre DR \& Singer FR. Biochemical assessment of boneformation and resorption in acromegaly. Journal of Clinical Endocrinology and Metabolism 199376 1452-1457.

2 Halse J \& Gordeladze JO. Urinary hydroxyproline excretion in acromegaly. Acta Endocrinologica $1978 \mathbf{8 9} 483-491$.

3 Kotzmann H, Bernecker P, Hubsch P, Pietschmann P, Woloszczuk W, Svoboda T, Geyer G \& Luger A. Bone mineral density and parameters of bone metabolism in patients with acromegaly. Journal of Bone and Mineral Research 19938 459-465.

4 Kayath MJ \& Vieira JG. Osteopenia occurs in a minority of patients with acromegaly and is predominant in the spine. Osteoporosis International $1997 \mathbf{7 2 2 6 - 2 3 0 .}$

5 Halse J, Melsen F \& Mosekilde L. Iliac crest bone mass and remodelling in acromegaly. Acta Endocrinologica 198197 18-22.

6 Bolanowski M. Daroszewski J. Medras M \& Zadrozna-Sliwka B. Bone mineral density and turnover in patients with acromegaly in relation to sex, disease activity, and gonadal function. Journal of Bone and Mineral Metabolism 200624 72-78.

7 Scillitani A, Chiodini I, Carnevale V, Giannatempo GM, Frusciante V, Villella M, Pileri M, Guglielmi G, Di Giorgio A, Modoni S, Fusilli S, Di Cerbo A \& Liuzzi A. Skeletal involvement in female acromegalic subjects: the effects of growth hormone excess in amenorrheal and menstruating patients. Journal of Bone and Mineral Research 199712 1729-1736.

8 Bijlsma JW, Nortier JW, Duursma SA, Croughs RJ, Bosch R \& Thijssen JH. Changes in bone metabolism during treatment of acromegaly. Acta Endocrinologica 1983104 153-159.

9 Terzolo M. Piovesan A. Osella G, Pia A, Reimondo G, Pozzi C, Raucci C, Torta M, Paccotti P \& Angeli A. Serum levels of bone Gla protein (osteocalcin, BGP) and carboxyterminal propeptide of type I procollagen (PICP) in acromegaly: effects of long-term octreotide treatment. Calcified Tissue International 199352 188-191.

10 Le Roith D, Bondy C, Yakar S, Liu JL \& Butler A. The somatomedin hypothesis. Endocrine Reviews 200122 53-74. 
11 Yakar S \& Rosen CJ. From mouse to man: redefining the role of insulin-like growth factor-I in the acquisition of bone mass. Experimental Biology and Medicine 2003228 245-252.

12 Aloia JF, Petrak Z, Ellis K \& Cohn SH. Body composition and skeletal metabolism following pituitary irradiation in acromegaly. American Journal of Medicine 197661 59-63.

13 Diamond T, Nery L \& Posen S. Spinal and peripheral bone mineral densities in acromegaly: the effects of excess growth hormone and hypogonadism. Annals of Internal Medicine $1989111567-573$.

14 Seeman E, Wahner HW, Offord KP, Kumar R, Johnson WJ \& Riggs BL. Differential effects of endocrine dysfunction on the axial and the appendicular skeleton. Journal of Clinical Investigation $1982691302-1309$.

15 Lesse GP, Fraser WD, Farquharson R, Hipkin L \& Vora JP. Gonadal status is an important determinant of bone density in acromegaly. Clinical Endocrinology $1998 \mathbf{4 8} 59-65$.

16 Longobardi S, Di Somma C, Di Rella F, Angelillo N, Ferone D, Colao A, Merola B \& Lombardi G. Bone mineral density and circulating cytokines in patients with acromegaly. Journal of Endocrinological Investigation $199821688-693$.

17 Scillitani A, Battista C, Chiodini I, Carnevale V, Fusilli S, Ciccarelli E, Terzolo M, Oppizzi G, Arosio M, Gasperi M, Arnaldi G, Colao A. Baldelli R, Ghiggi MR, Gaia D, Di Somma C, Trischitta V \& Liuzzi A. Bone mineral density in acromegaly: the effect of gender, disease activity and gonadal status. Clinical Endocrinology $2003 \mathbf{5 8} 725$ 731.

18 Bolanowski M, Wielgus W, Milewicz A \& Marciniak R. Axial bone mineral density in patients with acromegaly. Academic Radiology $20007592-594$.

19 Ho PJ, Fig LM, Barkan AL \& Shapiro B. Bone mineral density of the axial skeleton in acromegaly. Journal of Nuclear Medicine 199233 1608-1612.

20 Ueland T, Ebbesen EN, Thomsen JS, Mosekilde L, Brixen K, Flyvbjerg A \& Bollerslev J. Decreased trabecular bone biomechanical competence, apparent density, IGF-II and IGFBP-5 content in acromegaly. European Journal of Clinical Investigation 200232 122-128.

21 Bonadonna S, Mazziotti G, Nuzzo M, Bianchi A, Fusco A, De Marinis L \& Giustina A. Increased prevalence of radiological spinal deformities in active acromegaly: a cross-sectional study in postmenopausal women. Journal of Bone and Mineral Research $2005201837-1844$.

22 Morris PD, Malkin CJ, Channer KS \& Jones TH. A mathematical comparison of techniques to predict biologically available testosterone in a cohort of 1072 men. European Journal of Endocrinology $2004151241-249$.

23 Vermeulen A, Verdonck L \& Kaufman JM. A critical evaluation of simple methods for the estimation of free testosterone in serum. Journal of Clinical Endocrinology and Metabolism $1999 \mathbf{8 4}$ 3666-3672.
24 Vermeulen A. Hormonal cut-offs of partial androgen deficiency: a survey of androgen assays. Journal of Endocrinological Investigation 200528 28-31.

25 Godang K, Ueland T \& Bollerslev J. Decreased bone area, bone mineral content, formative markers, and increased bone resorptive markers in endogenous Cushing's syndrome. European Journal of Endocrinology 1999141 126-131.

26 de la PC, Larranaga J, Castro N, Horcajada C, Rapado A, Herrera Pombo JL \& Carbo E. Correlation among plasma osteocalcin, growth hormone, and somatomedin $\mathrm{C}$ in acromegaly. Calcified Tissue International $1988 \mathbf{4 3} 44-45$.

27 Marazuela M, Astigarraga B, Tabuenca MJ, Estrada J, Marin F \& Lucas T. Serum bone Gla protein as a marker of bone turnover in acromegaly. Calcified Tissue International $1993 \mathbf{5 2}$ 419-421.

28 Guicheux J, Heymann D, Rousselle AV, Gouin F, Pilet P, Yamada S \& Daculsi G. Growth hormone stimulatory effects on osteoclastic resorption are partly mediated by insulin-like growth factor I: an in vitro study. Bone 199822 25-31.

29 Kanatani M, Sugimoto T, Nishiyama K \& Chihara K. Stimulatory effect of insulin-like growth factor binding protein-5 on mouse osteoclast formation and osteoclastic bone-resorbing activity. Journal of Bone and Mineral Research 200015 902-910.

30 Hill PA, Reynolds JJ \& Meikle MC. Osteoblasts mediate insulin-like growth factor-I and -II stimulation of osteoclast formation and function. Endocrinology 1995136 124-131.

31 Jonsson KB, Wiberg K, Ljunghall S \& Ljunggren O. Insulin-like growth factor I does not stimulate bone resorption in cultured neonatal mouse calvarial bones. Calcified Tissue International 1996 59 366-370.

32 Ernst M \& Froesch ER. Growth hormone dependent stimulation of osteoblast-like cells in serum-free cultures via local synthesis of insulin-like growth factor I. Biochemical and Biophysical Research Communications 1988151 142-147.

33 Ueland T, Bollerslev J, Hansen TB, Ebbesen EN, Mosekilde L, Brixen K, Flyvbjerg A \& Djoseland O. Increased cortical bone content of insulinlike growth factors in acromegalic patients. Journal of Clinical Endocrinology and Metabolism 199984 123-127.

34 Gjesdal CG, Aanderud SJ, Haga HJ, Brun JG \& Tell GS. Femoral and whole-body bone mineral density in middle-aged and older Norwegian men and women: suitability of the reference values. Osteoporosis International 200415 525-534.

Received 11 May 2006

Accepted 30 August 2006 